\title{
DISTRIBUIÇÃO DAS TENSÕES EM NÚCLEOS METÁLICOS FUNDIDOS E PINOS EM FIBRAS DE VIDRO
}

Ana Paula Gebert de Oliveira FRANCO; Gislaine Cristina MARTINS; Eloísa de PAULA; Nerildo Luiz ULBRICH; Osnara Maria Mongruel GOMES

O objetivo desse estudo foi avaliar a distribuição das tensões em um dente canino superior (CS) reforçado com núcleo metálico fundido comparado a outro com pino em fibras de vidro. Foi realizada a construção de dois modelos de CS tratados endodonticamente, sendo um com núcleo metálico fundido e outro com pino em fibras de vidro, ambos reconstruídos com coroa de cerâmica pura, no programa AutoCAD 2000. Esses modelos foram transferidos para o Programa de Elementos Finitos (Ansys 7.0), onde foram determinadas as propriedades dos materiais (módulo de elasticidade e coeficiente de Poisson), construída uma malha de triângulos eqüiláteros, realizada a ancoragem em suas porções radiculares e aplicada uma carga mastigatória de $250 \mathrm{~N}$ a $45^{\circ}$ na superfície palatina dos dentes CS. Posteriormente, foram plotados os resultados e os mesmos foram analisados. Os resultados sugerem uma melhor distribuição da carga mastigatória nos pinos em fibras de vidro comparados aos núcleos metálicos fundidos. Conclui-se que os pinos em fibras de vidro apresentaram um comportamento biomecânico melhor que os núcleos metálicos fundidos, diminuindo os riscos de fraturas dentárias. 